\title{
Injection Scheme Optimization of Foam Profile Control on Block S103
}

\author{
Hongjun Yin ${ }^{1,2}$, Chuan Liu ${ }^{1,2}$, Meinan Wang ${ }^{1,2}$ \\ ${ }^{1}$ Accumulation and Development of Unconventional Oil and Gas, State Key Laboratory Cultivation Base Jointly-Constructed by \\ Heilongjiang Province and the Ministry of Science and Technology, Northeast Petroleum University, Daqing, China \\ ${ }^{2}$ Key Laboratory of Ministry of Education PRC, Northeast Petroleum University, Daqing, China \\ Email: Liuchuan67878@163.com
}

Received September 12, 2013; revised October 12, 2013; accepted October 19, 2013

Copyright (c) 2014 Hongjun Yin et al. This is an open access article distributed under the Creative Commons Attribution License, which permits unrestricted use, distribution, and reproduction in any medium, provided the original work is properly cited. In accordance of the Creative Commons Attribution License all Copyrights (C) 2014 are reserved for SCIRP and the owner of the intellectual property Hongjun Yin et al. All Copyright (C) 2014 are guarded by law and by SCIRP as a guardian.

\begin{abstract}
Facing problems with oil production decreasing quickly and water content increasing gradually in S103 well area, the Foam Profile Control was studied on the basis of its confirmed agent formula. The facies-controlled geological model of S103 well area was generated using random model based on Petrel software and using numerical simulation based on CMG software. Gas liquid alternating injection pattern was optimized as the optimal solution through the simulation optimization. Two months are optimized as the optimal solution through the simulation optimization. The cumulative oil production is $0.933 \times 10^{7} \mathrm{~kg}$ which is higher than the value of subsequent water flooding and the other three. Finally, it reaches the goals of slowing down the production decline and controlling the water rising.
\end{abstract}

\section{KEYWORDS}

\section{Foam Profile Control; Numerical Simulation; Injection Pattern; Injection Cycle}

\section{Introduction}

The technology of foam depth profile control has more than 30 years of history. Overseas, a research done by Marsden and Khan [1] concluded: Foam can slow down or even cut off the flow of high permeability zone, thus solving the problem of fluid injection displacement in the heterogeneous reservoir. The effect of $\mathrm{CO}_{2}$ foam flooding is studied by Owette [2]. Alexandrov [3] et al. studied the rule of foam filtration at porous medium. In our country, Li Zhengquan [4] verified that the foam based on polymer aqueous solution can improve the sweep efficiency of foam flooding; Du Qingjun [5] set up multicomponent mathematical seepage model of polymer; Pei et al. [6] analyzed the influence of gas fluid ratio, slug size, viscosity of crude oil on polymer aqueous based foam displacement efficiency. Nowadays, oil fields are in high water cut or in extremely high water cut; thus, water flooding problem is more and more complicated. Stabilizing oil water control technology, such as, profile control, is more and more difficult. The traditional small radius of profile control can no longer meet the requirements of stabilizing oil water $[7,8]$. The situation promotes the innovation and development of technology, especially in the application of the deep profile control liquid flow and improvement of the high water cut oilfield water injection [9].

This article selects the $\mathrm{P}$ reservoir of block S103, which has good reservoir properties. But there are lots of faults, oil and water distributing complexly. The effective thickness of average single well is only $3.1 \mathrm{~m}$, thus, after water breakthrough, water cut rises fast. Among them, the water cut of some areas where local sand body develops continuously has reached $60 \%$; thus the difficulty of development increases: the water flooding displacement efficiency is low and the cost of production rises. In this case, by the conventional adjustment technology, the remaining oil is often difficult to dig. It is less impossible to enhance oil recovery. Using foam profile control technology, this paper proposes a reasonable injection scheme by the injection of profile control agent in order 
to increase the sweep volume injection and change the underground flow field. The injection of medium can influence high oil saturation area, which can help to develop crude oil, slow down production decline, control water cut rising and improve oil recovery.

\section{Block S103 Numerical Simulation Research}

The $\mathrm{P}$ oil layer is the main mining of S103 block, oilbearing area is $2.56 \times 10^{6} \mathrm{~m}^{2}$, geological reserves is $99.54 \times 10^{7} \mathrm{~kg}$, recoverable reserves is $23.25 \times 10^{7} \mathrm{~kg}$, air permeability is $47.3 \times 10^{-15} \mathrm{~m}^{2}$ on average, the porosity is $22.7 \%$, crude oil density on the ground is $0.859 \times$ $10^{3} \mathrm{~kg} / \mathrm{m}^{3}$, average single well effective thickness of S103 block was $11.6 \mathrm{~m}$, the number of well there is 108 , of which the number of oil well is 81 and the number of water well is 27. By using Petrel and S103 block's actual geological data, we established a phased geological modeling which based on the method of random modeling. By CMG, we also establish a numerical model and tried to match the history in order to predict further development.

On the basis of establish fracture system, we divided S103 block into $137 \times 144=19728$ non-uniform angular point grid. By combining stratigraphic dip data, geological understanding and fracture system, we establish a reasonable structure model, which edge was based on the location of three major faults, and closed boundary was determined by strike. In order to guarantee the accuracy of the prediction scheme of initial conditions, we did mining history matching first, the fitting time was August 2000 to June 2011.

After forming initialization parameter field, in combination of geological, well logging and reservoir engineering analysis data, we revised the porosity, effective thickness and other uncertain parameters, after many pretreatment check, pre-processing, iterative fitting, the initialization of the reserves calculation is accordance with geological reserves, fitting reserves was $194.55 \times$ $10^{7} \mathrm{~kg}$. As shown in Table 1.
Fitting to June 2012, the actual integrated moisture content was $17.56 \%$, which the fitting of integrated moisture content was $17.98 \%$, the error was $2.4 \%$. The moisture content of producing fluid volume and fitting are shown in Figures 1 and 2.

\section{Research of Profile Control Agent Injection Solution in P Oil Layer of Block S103}

\subsection{The Determination of Profile Control Well Group}

There were 77 wells drilled in P oil layer in block S103, 21 of them were water wells, which the rest were oil wells. Among them, the number of wells that are high in water cut oil is 14 (see Table 2), which mainly distributed in the center of block S103.

The blocks in high water cut wells were controlled by 7 water wells, they were S103, S58-44, S60-44, S61-43,

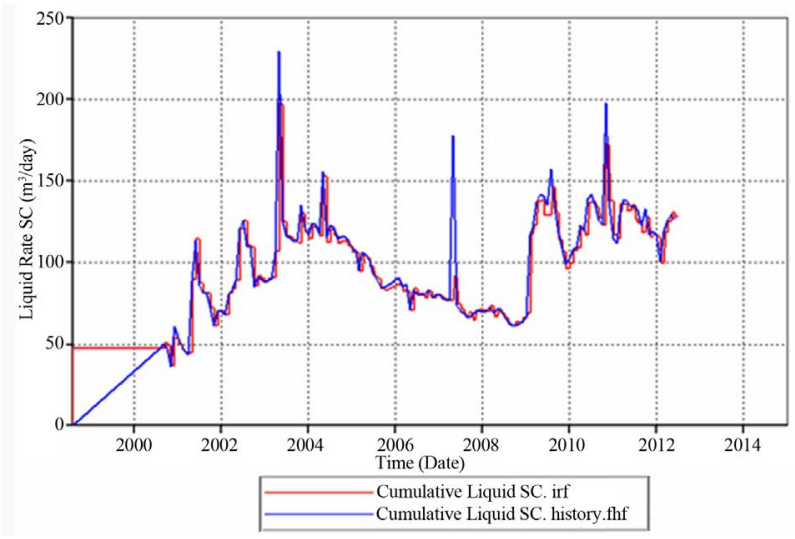

Figure 1. Fitting curve of fluid withdrawal rate in S103 wellblock.

Table 1. Reserves fitting results.

\begin{tabular}{ccc}
\hline $\begin{array}{c}\text { Geological reserves } \\
\left(10^{7} \mathrm{~kg}\right)\end{array}$ & $\begin{array}{c}\text { Fitting of reserves } \\
\left(10^{7} \mathrm{~kg}\right)\end{array}$ & $\begin{array}{c}\text { The relative } \\
\text { error }(\%)\end{array}$ \\
\hline 193.54 & 194.55 & 0.52 \\
\hline
\end{tabular}

Table 2. High water cut oil wells in P reservoir of block S103.

\begin{tabular}{cccc}
\hline Well no. & Injection speed $\left(\mathrm{m}^{3} / \mathrm{d}\right)$ & Well no. & Injection speed $\left(\mathrm{m}^{3} / \mathrm{d}\right)$ \\
\hline $\mathrm{S} 58-42$ & 77.46 & $\mathrm{~S} 62-45$ & 44.11 \\
$\mathrm{~S} 58-45$ & 42.68 & $\mathrm{~S} 62-46$ & 46.21 \\
$\mathrm{~S} 60-45$ & 70.70 & $\mathrm{~S} 62-49$ & 83.75 \\
$\mathrm{~S} 61-44$ & 48.98 & $\mathrm{~S} 63-41$ & 64.80 \\
$\mathrm{~S} 61-47$ & 74.43 & $\mathrm{~S} 63-44$ & 55.60 \\
$\mathrm{~S} 62-43$ & 81.11 & $\mathrm{~S} 63-46$ & 63.21 \\
$\mathrm{~S} 62-44$ & 43.60 & $\mathrm{~S} 64-42$ & 83.75 \\
\hline
\end{tabular}




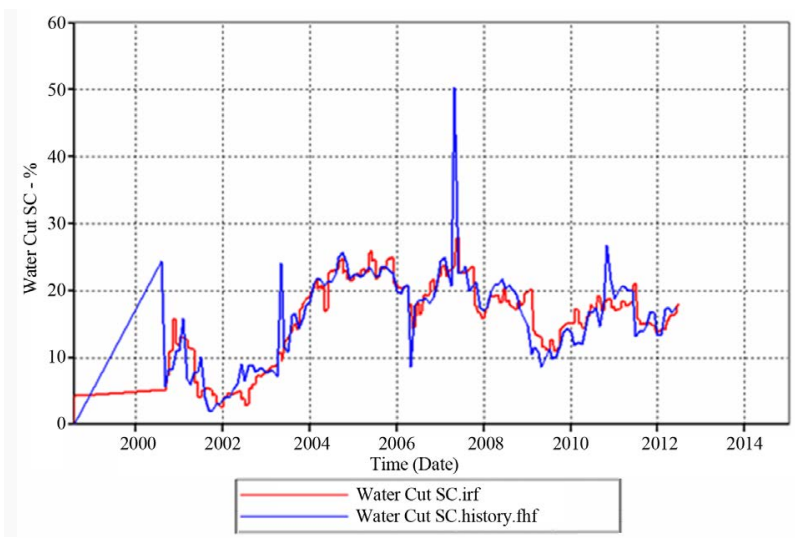

Figure 2. Fitting curve of the composite water cut in S103 wellblock.

S61-45, S63-43, S63-45. We selected S63-45, a high water cut wells, as the research object. Wells S63-45 is connected by 8 oil wells, they were S62-44, S62-45, S62-46, S63-44, S63-46, S64-44, S64-45, S64-46, as shown in Figure 3.

\subsection{Reasonable Injection Pattern Optimization}

There are two ways of foam profile control agent injection: gas-liquid mixing injection and gas-liquid alternating injection. We design three kinds of profile control scheme to optimizating of the above two kinds of injection way, for using the foam profile control agent formula system is: the polymer molecular weight is 8 million, polymer concentration of $1 \mathrm{~kg} / \mathrm{m}^{3}$, the surfactant concentration is $0.25 w t \%$, gas liquid ratio of $1: 1$. Profile control scheme as follows:

Solution 1: since July 1, 2012 used the method of water flooding until the water cut reaches to $98 \%$.

Solution 2: since July 1st in 2012, the foam profile control agent was maxing injected; the injection rate was $1.273 \times 10^{-4} \mathrm{~m}^{3} / \mathrm{s}$, and then used the method of water flooding until the water cut reaches up to $98 \%$.

Solution 3: since July $1^{\text {st }}$ in 2012, the foam profile control agent had been alternating injected. $\mathrm{CO}_{2}$ was injected after the foaming agent solution was firstly injected with the two month injection cycle and the injection rate of $1.273 \times 10^{-4} \mathrm{~m}^{3} / \mathrm{s}$, and the subsequent water flooding ends until the water cut reaches up to $98 \%$.

Three profile control schemes were studied by numerical simulation method using CMG software in well group S63-45 of reservoir P in S103 block. According to simulation results, we draw out moisture content and oil content curve which changing with time, as shown in Figures 4 and 5.

Through Figures 4 and 5, we can see that after profile control by different injection ways, after a period of time, moisture content will continue to rise, oil production will continue to fall, which means profile control measures is

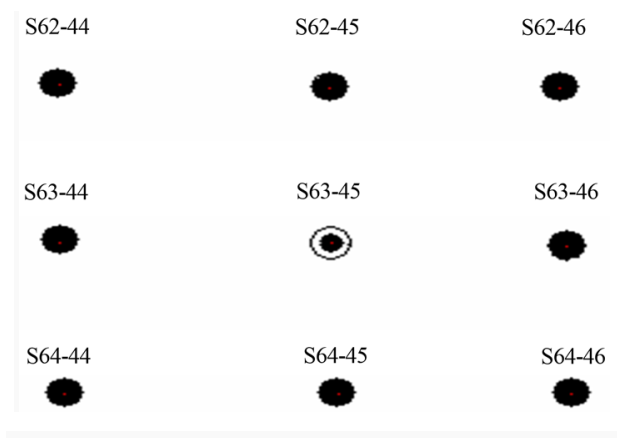

Figure 3. Location map of Well group S63-45.

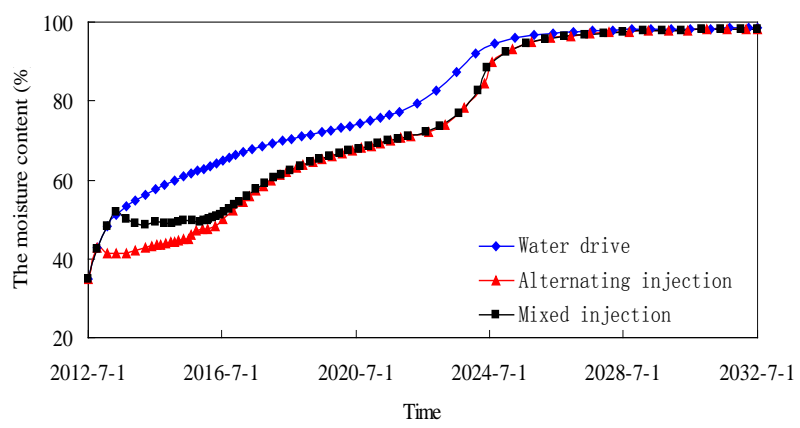

Figure 4. Test well group comprehensive water cut curve over time under different injection modes.

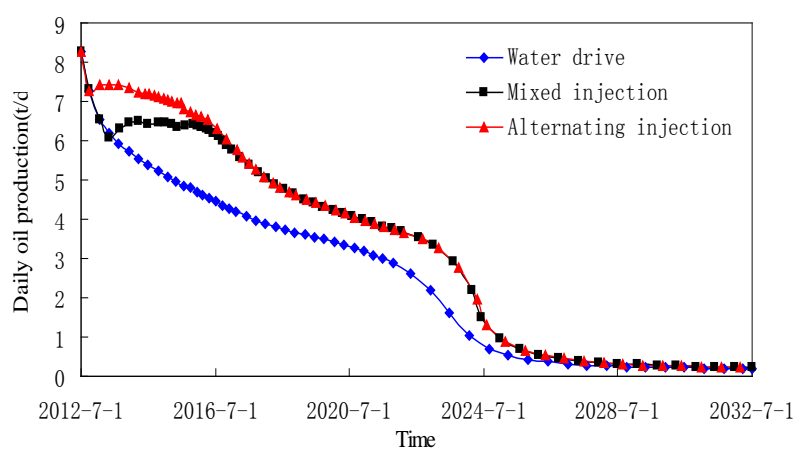

Figure 5. Oil production changing with time curve under different injection modes.

not work, then the moisture content decline, oil production rising, which shows that profile control measures work. We concluded that about nine months after the mixed way would be effective, about 3 months after the alternating injection way would be effective. Alternating injection decreases the moisture content and increases the oil content, which shows that the effect of alternating injection profile control is better than mixing injection.

Table 3 shows oil production and the change of moisture content after the profile control measures are adopted by profile control well group under the different injection ways.

We can see from the Table 3, oil wells with the highest cumulative oil production is alternating injection mode in research block, $13.750 \times 10^{7} \mathrm{~kg}, 0.933 \times 10^{7} \mathrm{~kg}$ 
Table 3. Profile control simulation results by different injection ways.

\begin{tabular}{|c|c|c|c|c|c|c|c|}
\hline Solution & $\begin{array}{l}\text { Injection pat- } \\
\text { tern }\end{array}$ & $\begin{array}{l}\text { Cumulative } \\
\text { oil production } \\
\left(10^{7} \mathrm{~kg}\right)\end{array}$ & $\begin{array}{c}\text { Than water } \\
\text { flooding on oil } \\
\text { increase }\left(10^{7} \mathrm{~kg}\right)\end{array}$ & $\begin{array}{l}\text { The } \\
\text { highest rising } \\
\text { oil }(\mathrm{kg} / \mathrm{s})\end{array}$ & $\begin{array}{l}\text { Within the profile control } \\
\text { measures the average } \\
\text { growing oil }\left(10^{3} \mathrm{~kg}\right)\end{array}$ & $\begin{array}{l}\text { High moisture } \\
\text { content value (\%) }\end{array}$ & $\begin{array}{l}\text { Profile control measures } \\
\text { average moisture content } \\
\text { decreases in value (\%) }\end{array}$ \\
\hline 1 & Water drive & 12.817 & - & - & - & - & - \\
\hline 2 & Mixed injection & 13.583 & 0.767 & 100 & 0.57 & 9.16 & 4.50 \\
\hline 3 & $\begin{array}{l}\text { Alternating } \\
\text { injection }\end{array}$ & 13.750 & 0.933 & 174.59 & 1.39 & 15.94 & 10.97 \\
\hline
\end{tabular}

higher than to water drive, $0.167 \times 10^{7} \mathrm{~kg}$ higher than mixed injection; during July 1, 2012 and July 1, 2015 the decline of average growing oil and average daily moisture content in profile control measures are higher than in mixed injection, which shows that alternating injection profile control effect is better than mixed injection.

\subsection{Reasonable Injection Cycle}

Foam profile control effect is not the same under different injection cycles. In determining the injection pattern of alternating injection, there are four design solutions for injection cycle, profile control scheme as follows:

Solution 4: foam profile control agent was injected in the form of alternating injection since July 1, 2012, the injection cycle is 2 months, the injection rate is $11 \mathrm{~m}^{3} / \mathrm{d}$, the time profile control is 3 years, then water flooding to $98 \%$ water cut.

Solution 5: foam profile control agent was injected in the form of alternating injection since July 1, 2012, the injection cycle is 4 months, the injection rate is $1.273 \times$ $10^{-4} \mathrm{~m}^{3} / \mathrm{s}$, the time of profile control is 3 years, then water flooding to $98 \%$ water cut.

Solution 6: foam profile control agent was injected in the form of alternating injection since July 1, 2012, the injection cycle is 6 months, the injection rate is $1.273 \times$ $10^{-4} \mathrm{~m}^{3} / \mathrm{s}$, the time of profile control is 3 years, then water flooding to $98 \%$ water cut.

Solution 7: foam profile control agent was injected in the form of alternating injection since July 1, 2012, the injection cycle is 12 months, the injection rate is $1.273 \times$ $10^{-4} \mathrm{~m}^{3} / \mathrm{s}$, the time of profile control is 3 years, then water flooding to $98 \%$ water cut.

According to the results of the simulation output, we drew curves to show the change of moisture content and oil content with time (as shown in Figures 6 and_7).

We can see from Figures 6 and 7, when taking different injection cycles for profile control after a period of time, moisture content will continue to rise, and oil production continues to fall, profile control measures is not effective in this period of time, then the moisture content decreases, the oil production increases, which show that profile control measures are effective. When the injection cycle is 2 months, the result is shown earliest; however,

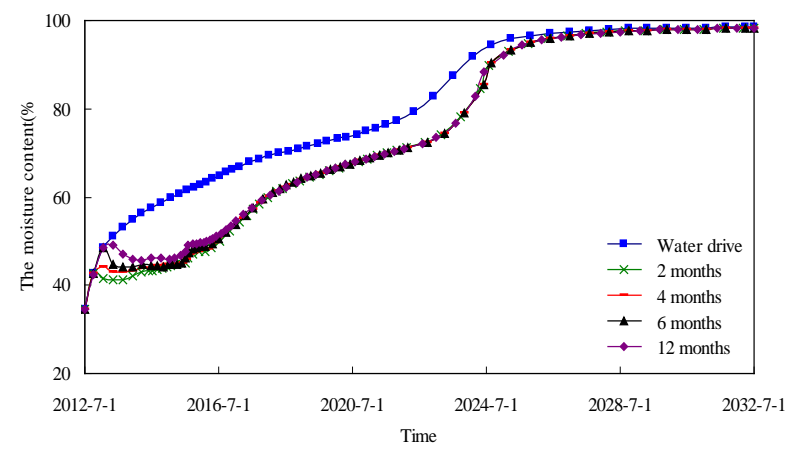

Figure 6. Comprehensive water cut curve of change over time of test well group under different injection cycle.

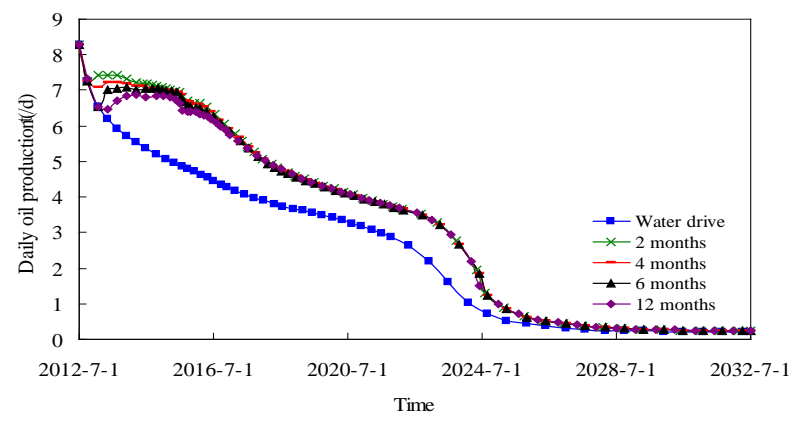

Figure 7. The curves of daily oil production over time of test well group under different injection cycles.

when injection cycle is 1 year, the result is shown latest. Thus we can conclude that the shorter the injection cycle, the more obvious of the increase of the moisture content and oil production rate.

Table 4 shows cut oil production after the profile control well group profile control measures and the change of moisture content under the different injection cycle.

We can see from the Table 4, the shorter the injection cycle, the higher cumulative oil production of oil wells in block, the average oil increases, daily average moisture content decreases under the profile control measures. The best effect of profile control can be seen when the injection cycle is 2 months, the cumulative oil production of $13.750 \times 10^{7} \mathrm{~kg}$, higher than to water drive by $0.933 \times$ $10^{7} \mathrm{~kg}$, and also higher than other injection cycle. That indicates that the injection cycle of foam profile control agent is 2 months in $\mathrm{P}$ oil layer. 
Table 4. Profile control simulation results of different injection cycles.

\begin{tabular}{|c|c|c|c|c|c|c|c|}
\hline Solution & $\begin{array}{l}\text { Injection } \\
\text { pattern }\end{array}$ & $\begin{array}{l}\text { Cumulative } \\
\text { oil production } \\
\left(10^{7} \mathrm{~kg}\right)\end{array}$ & $\begin{array}{c}\text { Than water } \\
\text { flooding on oil } \\
\text { increase }\left(10^{7} \mathrm{~kg}\right)\end{array}$ & $\begin{array}{l}\text { The highest } \\
\text { rising oil (kg/s) }\end{array}$ & $\begin{array}{l}\text { Within the profile control } \\
\text { measures the average } \\
\text { growing oil }\left(10^{3} \mathrm{~kg}\right)\end{array}$ & $\begin{array}{c}\text { High moisture } \\
\text { content value (\%) }\end{array}$ & $\begin{array}{c}\text { Profile control measures } \\
\text { average moisture content } \\
\text { decreases in value (\%) }\end{array}$ \\
\hline 4 & 2 months & 13.750 & 0.933 & 174.59 & 1.39 & 15.94 & 10.97 \\
\hline 5 & 4 months & 13.732 & 0.915 & 169.40 & 1.25 & 15.48 & 9.83 \\
\hline 6 & 6 months & 13.713 & 0.897 & 160.76 & 1.17 & 14.68 & 9.23 \\
\hline 7 & 12 months & 13.684 & 0.868 & 140.02 & 0.97 & 12.79 & 7.66 \\
\hline
\end{tabular}

\section{Conclusion}

1) According to the production characters of $P$ reservoir of S103 block, we determine 14 high water cut oil wells and 7 water wells connected with them, and apply the profile control measures to water wells S63-45.

2) When it comes to the selection of the injection mode, the effects of alternating profile control injection work are six months earlier than the mixed injection; the cumulative oil production of alternating profile control injection is higher than mixed injection by $0.167 \times 10^{7} \mathrm{~kg}$; the value of the average water cut is lower than mixed injection by $6.47 \%$. These data show that alternating injection is better than mixed injection.

3) On the injection cycle, when the injection cycle is 2 months, cumulative oil production is $13.75 \times 10^{7} \mathrm{~kg}$, and the water cut decreases by $10.97 \%$. The scheme is better than others, so the reasonable injection cycle of foam profile control agent is 2 months in layer $\mathrm{P}$ of block S103.

\section{REFERENCES}

[1] Z. L. Khatib, G. J. Hirasaki and A. H. Falls, "Effects of Capillary Pressure on Coalescence and Phase Mobilities in Foams Flowing Through Porous Media,” SPE Reservoir Engineering, Vol. 3, No. 3, 1988, pp. 919-926. http://dx.doi.org/10.2118/15442-PA

[2] A. W. Fisher, R. W. S. Fouiser and S. G. Goodyear, "Mathematical Modeling of Foam Flooding," SPE/DOE
Enhanced Oil Recovery Symposium, Tulsa, 22-25 April 1990, pp. 231-240. http://dx.doi.org/10.2118/20195-MS

[3] E. M. Ozbayoglu, S. Akin and T. Eren, "Foam Characterization Using Image processing Techniques,” SPE Western Regional Meeting, Irvine, 30 March-1 April 2005, pp. 1-8.

[4] Z. Q. Li, G. H. Zhou and Z. M. Zhou, "The Feasibility Studies of Polymer Foam Flooding in Gudao Oilfield," SPE Asia Pacific Oil \& Gas Conference and Exhibition, Adelaide, 11-13 September 2006, pp. 1-8.

[5] Q. J. Du, J. Hou, Z. Q. Li, Y. D. Wang and Y. M. Chen, "A Mathematical Model of Polymer Enhanced Foam Flooding," Chinese Journal of Computational Physics, Vol. 26, No. 6, 2009, pp. 872-878.

[6] H. Pei, G. Zhang, J. Ge, J. Wang, B. Ding and X. Liu, "Investigation of Polymer-Enhanced Foam Flooding with Low Gas/Liquid Ratio for Improving Heavy Oil Recovery," Canadian Unconventional Resources and International Petroleum Conference, Calgary, 19-21 October 2010, pp. 1-11. http://dx.doi.org/10.2118/137171-MS

[7] Q. L. Gang, "High Water Cut Stage Oilfield New Technologies to Improve Water Flooding Effect (on)," 1st Edition, Petroleum Industry Press, Beijing, 1999.

[8] J. E. Smith, "Quantative Evaluation of Polyacrylamide Crosslinked Gels for Use in Enhanced Oil Recovery,” International ACS Symposium, Anahemi, September, 1986, pp. 9-12.

[9] X. F. Jia, G. L. Lei and X. Y. Jia, "Current Situation and Development Trend of In-Depth Profile Control,” Special Oil \& Gas Reservoirs, Vol. 16, No. 4, 2009, pp. 6-12. 